\title{
Hypothermic ante situm Resection in Tumors of the Hepatocaval Confluence
}

\author{
Ari Mehrabi Hamid Fonouni Mohammad Golriz Stefan Hofer \\ Mohammad Hafezi Nuh N. Rahbari Jürgen Weitz Markus W. Büchler \\ Jan Schmidt
}

Department of General, Visceral, and Transplantation Surgery, University of Heidelberg, Heidelberg, Germany

\section{Key Words}

Hypothermic liver preservation · Hepatocaval tumor •

Ante situm liver resection

\begin{abstract}
Primary liver malignancies together with metastatic liver tumors are among the most common tumors in human. The best available treatment option for these diseases is surgical resection. One major parameter which had been considered as contraindication for liver resection owing to technical difficulties in achieving tumor-free margins was the involvement of the hepatocaval confluence. To overcome this problem, several techniques including hypothermic in situ, ante situm and ex situ liver resection have been introduced. The common basis for these liver resections is the total vascular exclusion of the liver, and perfusion of the organ by preservation solution under hypothermic conditions. The major indications for the ante situm liver resection are tumors in the liver that are either unresectable or inadequately resectable by conventional surgery because they involve the venous confluence and/or the retrohepatic vena cava, or are in close proximity to them. This technique is a realistic option to achieve surgical cure or substantial gain of life time with quality of life in otherwise unresectable tumors of the liver.
\end{abstract}

Due to fewer anastomoses, the ante situm approach is easier and safer than the ex situ approach, with an acceptable morbidity and mortality rate. Patient selection is of utmost importance to achieve a good outcome. To minimize the postoperative morbidities and mortality, this procedure requires a multidisciplinary approach and should be performed in experienced centers with a high case volume of hepatobiliary surgeries.

Copyright $\odot 2011$ S. Karger AG, Basel

\section{Introduction}

The treatment of extensive liver tumors has undergone remarkable progress in recent decades. Primary liver malignancies such as hepatocellular carcinoma and cholangiocarcinoma together with metastatic liver tumors from other organs are among the most common tumors in human. The best available treatment option for these diseases is surgical resection [1]. The median 5 -year survival rate after liver resection reaches $30-50 \%$ if $\mathrm{R} 0$ is achieved, and in cases of R1/2 the survival decreases to a rate of $7 \%$ [2]. Untreated patients have a median survival of $<12$ months [3] and chemotherapy does not offer a curative option, with few 5 -year survivors reported [4]. Un-

\section{KARGER}

Fax +4161306 1234

E-Mail karger@karger.ch

www.karger.com
(C) 2011 S. Karger AG, Basel

$0253-4886 / 11 / 0282-0100 \$ 38.00 / 0$

Accessible online at:

www.karger.com/dsu
Dr. Arianeb Mehrabi, MD, FEBS, FICS

Department of General, Visceral and Transplantation Surgery

University of Heidelberg, Im Neuenheimer Feld 110

DE-69120 Heidelberg (Germany)

Tel. +496221 563 6223, E-Mail arianeb_mehrabi@med.uni-heidelberg.de 
derstanding of the specific anatomy and physiology of the liver has continuously opened new ways in liver surgery and provided successful treatment for many tumors, which were previously considered technically inoperable. In addition, neoadjuvant chemotherapy as well as embolization of the left or right portal vein in conjunction with resection have become established procedures, especially in the treatment of advanced, bilobar liver metastases [5]. Under certain conditions, primary liver tumors can be managed by liver transplantation. In this context, appropriate multi-modal concepts to achieve R0 situation can provide a long-term survival.

Many hepatic tumors are conventionally unresectable because of their diffuse distribution or broad infiltration of essential vascular structures $[6,7]$. One of the major parameters which had been considered as contraindication for liver resection owing to technical difficulties in achieving tumor-free margins was the involvement of the hepatocaval confluence [8]. For large, centrally located tumors with invasion of the venous outflow tract and/or the retrohepatic vena cava, adopting a curative approach with the classical methods of multimodal therapy is often impossible. However, these types of tumors would be potentially resectable if they were better accessible, or if there was adequate time available for precise preparation and/or vascular reconstruction. The safe time limit of liver tolerance to total vascular occlusion seems to be 60-90 min [9], which is short for extensive and complex tumors with direct contact to major vascular structures. Factors such as preoperative portal vein embolization (PVE) and/ or large tumors are predictive for total vascular exclusion $>60$ min [10]. A long total vascular exclusion may lead to severe hepatic ischemia, hemodynamic disturbances and potential renal injury $[11,12]$. The postischemic reperfusion damage to the liver is reported especially in cirrhotic or severely steatotic livers [13]. To overcome this limitation and to reduce liver damage, the concept of hypothermic perfusion has come into consideration. It has been shown that every $10^{\circ} \mathrm{C}$ decline in temperature of liver parenchyma decreases the liver enzyme activity by $1.5-2$ fold [14].

The in situ hypothermic liver preservation technique was first introduced by Heaney et al. [15] in 1966 and Fortner et al. [16] in 1974. In this technique, the liver is flushed with preservation solution at $4^{\circ} \mathrm{C}$ and packed with ice during the period of total vascular exclusion [8]. The adjunction of hypothermic perfusion to the liver resection has been reported to prolong safely the vascular exclusion up to several hours [10]. However, in the case of tumors located on the dorsal side of the liver with exten-

Hypothermic ante situm Liver Resection sion to the liver veins and/or inferior vena cava (IVC), the in situ hypothermic liver resection is technically not feasible. To overcome this problem, first the ex situ (ex vivo) liver resection had been described by Pichlmayr et al. [17] in 1990, in which the whole liver is explanted and then perfused with cold preservation solution. The hepatic resection is performed on the back table and the remnant liver is reimplanted orthotopically. The aim of the extracorporeal hypothermic parenchymal resection was the extension of oncological radicality by achieving an R0 margin with a better tumor-free cutting edge. The advantage of this technique, i.e. the possibility of complex reconstructive procedures of the hepatic veins, however, is counterbalanced by a significant morbidity and much higher mortality in comparison to conventional liver resection. Therefore, the ante situm technique of liver resection, which was first described by Hannoun et al. [18] in 1991, came into consideration. In this technique, after dividing the three hepatic veins or a segment of the IVC, the liver can be anteriorly mobilized out of the abdomen. Then, the liver is perfused with cold preservation solution through the portal vein and the resection phase is performed without the need for dividing the important structures of the liver hilum. During the hypothermic phase, the IVC and venous outflow reconstruction is performed with or without the use of autogenous or prosthetic grafts.

However, the questionable safety of the ante situm or ex situ methods and the absolute necessity of having sufficient experience in (split) liver transplantation have left the ante situm and in situ liver resection as an exceptional procedure which can only be performed safely in specialized centers. Our aim is to give an overview of the potential indications for hypothermic perfusion ante situm liver resection, to describe the safety and efficacy of this technique, and to present results of reported performed hypothermic in situ and ante situm liver resections.

\section{Indications for ante situm Liver Resection}

The major indications for the ante situm liver resection are tumors in the liver that are either unresectable or inadequately resectable by conventional surgery because they involve the venous confluence and/or the retrohepatic vena cava, or are in close proximity to them. The only alternative treatment for some of these patients might be liver transplantation. Ante situm resection can be indicated for different types of tumors, including pri- 
mary malignant hepatic tumors, metastatic tumors, and also some benign intrahepatic tumors. In addition, some extrahepatic tumors might also constitute an indication for hypothermic liver perfusion if they involve the retrohepatic vena cava close to the hepatic veins such as renal cell carcinomas or leiomyosarcomas of the vena cava [19]. In the series of 54 resections (in situ: 6, ante situm: 24 , ex situ: 22 cases) in 52 patients, which was reported by Raab et al. [20], the most frequent indication was liver metastasis (mainly colorectal); 15 patients suffered from primary malignant hepatobiliary tumors, and 5 patients had symptomatic benign lesions (focal nodular hyperplasia) or lesions of unclear identity that turned out to be benign (adenoma). Other groups reported in situ, ex situ, or ante situm resection techniques for similar indications [21]. The decision which type of resection technique is suitable mainly depends on the location of the tumor, and the exposure required for optimal resection and reconstruction. Although the operations in the past were performed using the ex situ technique, it is not advocated to remove the liver from the body completely but to mobilize it ventrally (ante situm) as much as necessary, since this avoids the additional morbidity of arterial and biliary reconstruction. With this approach, the ante situm technique would be the most appropriate technique in the majority of patients in whom the portal pedicle can usually be maintained. The final decision between in situ or ante situm resection can only be made intraoperatively [22].

Pichlmayr et al. [17] grouped the potential indications for these approaches into 3 categories. Category 1 refers to cases in whom conventional resection would be possible without the need for liver transplantation; category 2 contains the patients in whom conventional resection would not be radical and liver transplantation might provide an alternative of treatment. In such patients, the transplantation would not be the preferred choice of treatment. In this group, due to the non-radicality of conventional techniques, new approaches would be required, taking into account that liver transplantation would be potentially considered as a second-line treatment. Category 3 includes the patients in whom conventional resection is not possible, liver transplantation is contraindicated, and there are no other options of surgical treatment except advanced resection techniques. With the current organ shortage, hypothermic liver resection techniques seem reasonable in patients of categories 2 or 3, and provide the only chance of cure, or at least of substantial gain of life time [22]. However, the potential advantages and disadvantages of these techniques have to be weighed against each other and against those of conventional resection techniques in each individual patient.

Impaired liver function is considered a relative contraindication for applying the ante situm approach. Other groups, however, suggest that hypothermic perfusion techniques in particular - combined with only very limited dissection of the hepatoduodenal ligament - should be considered for resection in patients with impaired liver function [23]. They argue that such livers in particular would tolerate the warm ischemia during standard resection much less, and that hypothermic perfusion would provide a much safer way of resection $[23,24]$. The overall advantages and disadvantages of these techniques in patients with impaired liver function, however, are a matter of debate. If no other treatment option is available, resection under hypothermic perfusion may be considered, but the increased risk has to be acknowledged. In cases with cholestatic liver malfunction, preoperative biliary drainage of the liver should be considered to improve liver function prior to resection [22]. Our experience shows that the target bilirubin level to perform the resection safely should be below 5-10 mg/dl.

\section{Technical Aspects of ante situm Liver Resection}

The common basis for ante situm liver resection is total vascular exclusion of the liver, and perfusion of the organ by preservation solution under hypothermic conditions. After careful exploration of the abdominal cavity to rule out extrahepatic manifestation, a double examination of the liver by palpation and sonography should be performed to confirm the lesion and to evaluate the resectability of the tumor followed by confirmation of the planned resection line. For hypothermic perfusion, the hepatoduodenal ligament must be dissected, and the portal vein completely exposed and mobilized. Afterwards, the right and left liver lobes are completely mobilized, and the infra- and suprahepatic vena cava are mobilized for cross-clamping at least $1 \mathrm{~cm}$ above the hepatic veins. Thereafter, a perfusion cannula is inserted into the portal vein, and the infra- and suprahepatic vena cava is crossclamped. Then, perfusion is started with $4^{\circ} \mathrm{C}$ cold preservation solution, and the perfusion fluid is drained through an incision of either the infra- or suprahepatic vena cava. In our center, HTK solution (Bretschneider solution, Custodiol ${ }^{\circledR}$ ) is used for this procedure. Nevertheless, other groups were also successful with different preservation solutions such as University of Wisconsin (UW) solution [9]. The advantages of HTK solution may 
include an optimized buffer system (histidine), a very low viscosity which allows rapid and homogenous perfusion of the liver, and a low potassium content which decreases the risk of cardiac problems after reperfusion. Belghiti et al. [21] described a variation of the technique in which the vena cava is cut below the hepatic veins leading to better mobilization and performing the resection while the liver is being perfused through the portal vein. The division of the vena cava allows rotation of the liver around the coronary axis, and thus provides optimal exposure of the venous confluence and the retrohepatic vena cava. In the case of tumor infiltration of the vena cava, partial or complete resection and subsequent reconstruction of the retrohepatic caval vein can be done after completing the parenchymal phase of the liver resection. If a long vena cava segment has to be resected, reconstruction by alloplastic material [e.g. 20-mm ring PTFE (Goretex ${ }^{\circledR}$ ) graft] may be required. For shorter segments, reconstruction by autologous veins is preferred. If the IVC has to be replaced at the entry of the hepatic veins, direct anastomosis of hepatic veins into the PTFE graft may be performed (fig. 1 and 2). An alternative may be the caval shift operation of an infrarenal cava segment to replace the retrohepatic cava. The infrahepatic segment can then be replaced by a prosthesis.

\section{Review of the Literature}

We have reviewed available English and German reports regarding hypothermic in situ and ante situm liver resections with reconstruction of the hepatic venous outflow and/or reconstruction of IVC. Table 1 shows the results of the reviewed case series. Belghiti et al. [21] reported 3 cases of liver tumor resections by combining hypothermic portal perfusion with an anhepatic period of more than $2 \mathrm{~h}$ (ante situm). The tumors were cholangiocarcinoma in 2 cases and colonic metastasis in 1 case. Nontumoral liver parenchyma was normal in all cases. The IVC was involved by the tumor in 2 cases. Complete tumor resection was achieved in all patients, but required reconstruction of the hepatic veins in one case only. Two patients in whom portal venous bypass was not used developed hemodynamic failure after liver revascularization, and one of them died. Hannoun et al. [25] reported 3 patients with hepatocellular carcinoma, metastasis of colorectal carcinoma and a 'diffuse' hemangioma. Duration of cold ischemia was 225, 205, and $230 \mathrm{~min}$, respectively. The postoperative course was uneventful in all 3 cases, and patients were alive at 15 th, 12 th, and 6 th post-

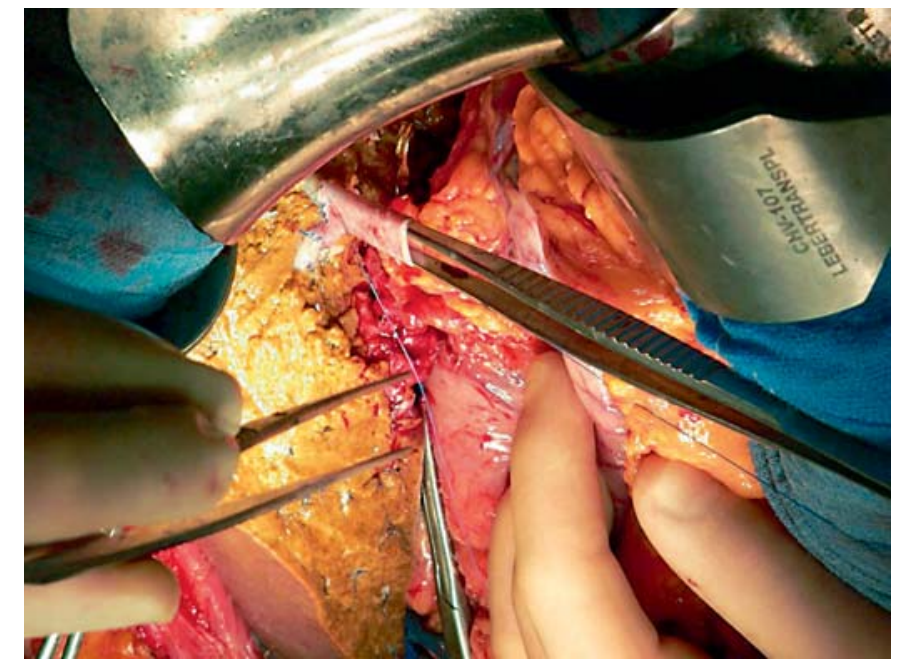

Fig. 1. Reconstruction of the hepatic veins of the remnant liver.

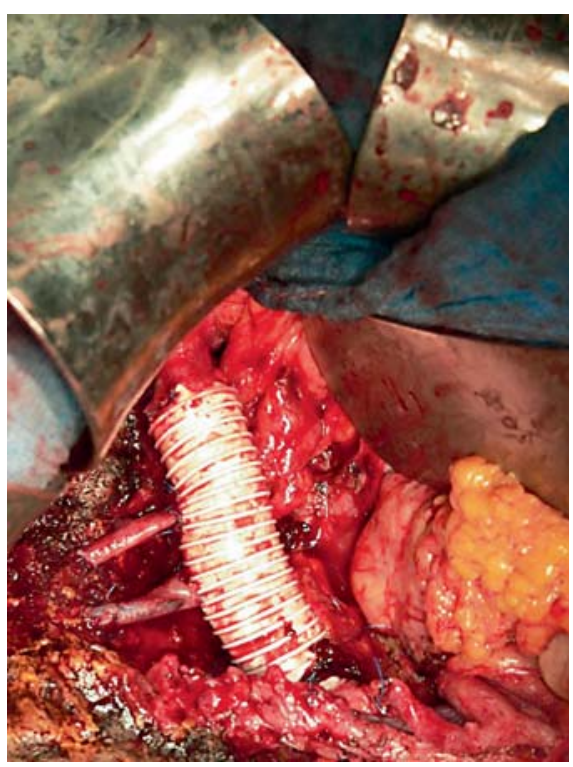

Fig. 2. Completed hepatic vein reinsertion into the IVC prosthesis.

operative month, respectively. Forni and Meriggi [26] reported 1 case of ante situm liver resection in 1995. The patient had hepatic metastasis from renal carcinoma. The patient died intraoperatively from a massive retroperitoneal bleeding. In the same year, Delriviere and Hannoun [23] performed ante situm resection in 4 cases which had uneventful courses. Fabre et al. [19] reported one patient with leiomyosarcoma who successfully underwent liver resection with complete vena cava replacement and dis- 
Table 1. Literature reports of hypothermic in situ and ante situm liver resections with reconstruction of the hepatic venous outflow

\begin{tabular}{|c|c|c|c|c|}
\hline Report & Year & Cases & Tumor type & Mortality \\
\hline Belghiti et al. [21] & 1991 & 3 & $\begin{array}{l}2 \text { cholangiocarcinoma } \\
1 \text { colonic cancer }\end{array}$ & 1 died \\
\hline Hannoun et al. [25] & 1991 & 3 & $\begin{array}{l}1 \text { hepatocellular carcinoma } \\
1 \text { colorectal cancer } \\
1 \text { diffused hemangioma }\end{array}$ & 0 died \\
\hline Forni et al. [26] & 1995 & 1 & - & 1 died \\
\hline Delriviere et al. [23] & 1995 & 4 & - & 0 died \\
\hline Fabre et al. [19] & 1995 & 1 & Leiomyosarcoma & 0 died \\
\hline Vaillant et al. [27] & 1998 & 4 & - & - \\
\hline Raab et al. [20] & 2000 & 23 & $\begin{array}{l}9 \text { colorectal cancer } \\
3 \text { breast cancer } \\
2 \text { hypernephroma } \\
2 \text { leiomyosarcoma } \\
2 \text { hepatocellular carcinoma } \\
1 \text { pheochromocytoma } \\
1 \text { cholangiocellular carcinoma } \\
1 \text { hepatoblastoma } \\
1 \text { focal nodular hyperplasia } \\
1 \text { adenoma } \\
1 \text { Echinococcus alveolaris }\end{array}$ & $\begin{array}{l}\text { ante situm and in } \\
\text { situ liver resection } \\
\text { less than ex situ }\end{array}$ \\
\hline Azoulay et al. [28] & 2006 & 9 & $\begin{array}{l}6 \text { metastasis (unclear) } \\
2 \text { cholangiocarcinoma } \\
1 \text { hepatocellular carcinoma }\end{array}$ & 1 died \\
\hline Hemming [30] & 2008 & 8 & - & - \\
\hline Dubay et al. [8] & 2009 & 9 & $\begin{array}{l}4 \text { vena cava leiomyosarcoma } \\
2 \text { intrahepatic cholangiocarcinoma } \\
1 \text { perihilar cholangiocarcinoma } \\
1 \text { malignant schwannoma } \\
1 \text { colorectal metastasis }\end{array}$ & 2 died \\
\hline Kim et al. [29] & 2009 & 1 & rectum cancer & 0 died \\
\hline Our case series & 2010 & 7 & $\begin{array}{l}4 \text { cholangiocarcinoma } \\
2 \text { colorectal metastases } \\
1 \text { hepatocellular carcinoma }\end{array}$ & 0 died \\
\hline
\end{tabular}

obliteration of the hepatic veins under venovenous bypass and liver hypothermic perfusion, the so called 'ex situ, in vivo liver surgery'. In 1998, Vaillant et al. [27] reported 4 cases of 'ex situ-in vivo' liver resection. The biggest case series of ante situm liver resection was reported by Raab et al. [20] in 2000. They performed 54 extracorporeal liver resections in 52 patients, of whom 24 underwent ante situm liver resections. The most frequent indications for ante situm resection were colorectal and breast cancer metastases, hypernephroma, hepatocellular carcinoma and leiomyosarcoma. Overall, the morbidity and mortality rate was $30 \%$, which was highest in ex situ and lower in ante situm and in situ resections, without mentioning the rate in each procedure. The median survival of patients with colorectal metastases was 21 months. Azoulay et al. [28] reported 9 cases of liver resection with in situ cold perfusion of the liver. The tumors were metastasis in 6 cases, cholangiocarcinoma in 2 cases and he- 
patocellular carcinoma in 1 case. The mean follow-up duration was about 19 months (range: 11-60). Only one patient died (4.5\%) due to catheter infection, 7 days after in situ cold perfusion with the vena cava reconstruction. In a study conducted by Dubay et al. [8] in 2009, overall 9 patients underwent in situ hypothermic perfusion liver resection, and vena cava reconstruction was performed in 7 of them. In their series, the median duration of operation, estimated blood loss, intensive care unit stay and hospital stay were $540 \mathrm{~min}, 1,500 \mathrm{ml}, 2$ days, and 18 days, respectively. No intraoperative deaths were reported, but one in-hospital mortality due to progressive postoperative liver failure, and one mortality 14 months after operation due to distant metastasis of cholangiocarcinoma. Kim et al. [29] reported a 58-year-old man who was diagnosed with liver metastasis from rectal cancer and underwent liver resection through ante situm technique with 12-month follow-up without recurrence. In our center, we have performed seven ante situm hepatic resections combined with hypothermic perfusion ( 3 males and $4 \mathrm{fe}$ males). Their ages ranged from 44 to 62 years, with a median of 52 years. The indications were central cholangiocarcinoma $(n=4)$, colorectal metastases $(n=2)$ and hepatocellular carcinoma $(n=1)$. Free of tumor $(R 0)$ margins were achieved in 5 cases; in one case, the microscopic status of surgical margins could not be ascertained ( $\mathrm{Rx})$ due to thermal artifacts, and in one case, microscopic tumor invasion (R1) was demonstrated histopathologically (table 1). All patients except one are free of tumor with a follow-up of 10 months.

\section{Discussion}

Patients with liver tumors extending to the hepatic venous confluence and/or IVC are considered poor candidates for surgery [30]. However, untreated patients have a poor survival rate [3] despite undergoing chemotherapy [4]. In this regard, surgical modalities including in situ $[15,16]$, ex situ [17] and ante situm [25] hypothermic liver resection techniques have been developed. The ante situm technique of liver resection, which was first described by Hannoun et al. [25] is preferred in tumors of the liver located centrodorsally extending to the hepatic venous confluence and/or retrohepatic IVC [6]. In this technique, the hepatic veins are excised allowing the mobilization of the liver ventrally (ante situm) [8]. Thereafter, the liver is perfused with preservation solution via portal vein and the parenchymal resection is done. After the resection phase, the hepatic veins are reconstructed and reimplanted to the IVC or, in case of IVC infiltration, to the interposition graft [10]. The ante situm hypothermic liver resection technique has proved to be applicable in so-called conventionally 'inoperable tumors' to enable radical surgery in tumors extending to major hepatic vasculature. The induced hypothermia lowers the cellular metabolism, and decreases the ischemic cell injury providing enough time to accomplish the resection and reconstruction precisely [31].

Regarding preoperative evaluation and patient selection, diagnostic imaging such as intraoperative ultrasonography, thin cut or 3-D volumetric CT reconstruction, and indocyanine green clearance and possibly the newly developed Limax test $[32,33]$ are important preoperative evaluative modalities especially in low-grade cirrhotic patients to provide an exact image of the proposed remnant liver and assess the liver function [9]. The most important factor in selecting the patients suitable for ante situm resection is the preoperative liver function, with exclusion of cirrhotic patients or compromised liver parenchyma (steatosis/fibrosis) that have an inadequate hepatocellular reserve [30]. Therefore, preservation of a functional mass during resection and trying to reach a negative oncologic margin are two challenging factors [9]. This technique is suitable in cases in which the tumor is confined to the liver without lymph node infiltration $[29,34]$. The value of preoperative modalities including transarterial chemoembolization, PVE and staged resection, as well as neoadjuvant chemotherapy remains to be assessed in the future. It has been already shown that effective chemotherapy allows downstaging the tumors in $20 \%$ of cases [35]. Hemming et al. [9] advocated doing PVE in cases with future remnant liver less than $25 \%$ if vascular reconstruction is not necessary, or $40 \%$ if IVC and/or hepatic vein reconstruction is necessary based on 3-D imaging.

Patient selection and the general state of health are two important factors that should be assessed meticulously. Melendez et al. [36] showed that accompanying cholangitis, creatinine $>1.3 \mathrm{mg} / \mathrm{dl}$, total bilirubin $>6 \mathrm{mg} / \mathrm{dl}$, intraoperative blood loss $>3$ liters, and IVC resection are independent predictive factors of mortality risk in patients undergoing extended hepatic resection. As a general rule, the patients who are young enough to tolerate extensive surgery and have enough hemodynamic reserve, no or minimal accompanying disorders, localized tumors with no metastases, no liver cirrhosis and who are likely to comply with routine follow-up can be considered for this procedure. Another important preoperative factor is the institutional case load. It has been shown that performing extended hepatobiliary surgeries in high-vol- 
ume centers is associated with better outcome [37-42]. Interestingly, there was no difference between transplant and experienced hepatobiliary surgeons in terms of better outcome [38].

Liver resection along with excision and reconstruction of the IVC and/or liver veins is a challenging operation with high rate of morbidity and mortality reported from 9 to $33 \%$, especially in ex situ resections [9]. Nevertheless, in studies conducted by Miyazaki et al. [43] and Hemming et al. [9], the 5-year survival rate following combined liver and IVC resection was 22 and 33\%, respectively. In the early postoperative phase, the most frequent complications are bleeding, infection, bile fistula, bilio$\mathrm{ma}$, ascites, liver failure in the case of extended resection in cirrhotic patients, and respiratory complications. With regard to the comparison of the ex situ and ante situm technique, it has been shown that the 'ex situ' liver resections introduced by Pichlmayr et al. [17] in conventionally inoperable, primary and secondary liver tumors have been abandoned due to significant morbidity and mortality as high as $28 \%$. For all techniques requiring caval replacement, venovenous bypass could be necessary in some cases because of hemodynamic instability reflecting a decrease of more than $30 \%$ in mean arterial pressure and/or more than 50\% in cardiac index. Additionally, in contrast to the 'ex situ' resection, in the 'ante situm' technique, there is no need for the reconstruction of the hepatic inflow, resulting in a significant reduction of the morbidity and mortality rate.

One of the major advantages of using hypothermic perfusion and cooling as compared to the conventional techniques is the markedly prolonged ischemic tolerance, and the opportunity of extensive mobilization of the liver that provides optimal access to the posterior areas. The major advantage compared to transplantation is that there is no need for long-term immunosuppression, which is associated with complications that may also include stimulating effects on tumor growth. Furthermore, due to the shortage of organs, it seems justified to apply such a complex procedure in those for whom otherwise there is no curative option available. The major disadvantage of in situ and ante situm liver resection is an increased risk of postoperative liver failure, particularly if the liver function was already impaired preoperatively due to underlying liver disease or chemotherapy. On the other hand, the reported postoperative mortality up to $28 \%$, specifically in ex situ resection, and in some cases the need for salvage liver transplantation due to hepatic failure calls for care in applying this technique [44-46]. After adequate consideration of potential advantages and disadvantages of all available alternatives, however, these techniques may turn out to be the most appropriate approach in certain patients [22].

One of the most important prerequisites for this procedure is experience in conventional extensive liver resection or in the field of various liver transplantation techniques. In addition to the technical challenges of surgery, the requirement for optimal perioperative intensive care is crucial. Furthermore, with the increasing experience in managing early postoperative complications, tumor recurrence and metastases were responsible for the disappointing long-term results [44]. The success of the rapidly evolving, individualized neoadjuvant and adjuvant therapy justified the high operating costs of this procedure. This is particularly true in the light of poor prognosis, with an extremely short life expectancy without conventional surgical therapy. In such an exceptional indication, the complete explanation of the procedure and involvement of the patient is of great importance. In contrast to a palliative treatment with no prospect of cure with a life expectancy of few months $[47,48]$, this procedure offers potentially curative surgery with a perspective to provide a good quality of life. Future investigations should analyze whether the ambitious resumption of extracorporeal liver resection technique in primary and secondary liver tumors could allow a long-term survival in conventionally inoperable patients.

In conclusion, extracorporeal liver resections using the 'ante situm' technique can be carried out safely with an optimal access to the tumor. This technique is a realistic option to achieve surgical cure or substantial gain of life time with quality of life in otherwise unresectable tumors of the liver. Due to fewer anastomoses, the ante situm approach is easier and safer than ex situ with an acceptable morbidity and mortality rate. The indication and patient selection is of utmost importance to achieve better outcomes. This procedure requires a multidisciplinary approach and should be performed in experienced centers with a high volume of hepatobiliary surgeries to minimize postoperative morbidities and mortality. Finally, this procedure has now its own place in the armamentarium of advanced liver surgery and can be considered a valuable option for selected patients in whom no other curative alternative is available.

\section{Disclosure Statement}

The authors have nothing to disclose. 


\section{References}

1 Abrams P, Marsh JW: Current approach to hepatocellular carcinoma. Surg Clin North Am 2010;90:803-816.

$\checkmark 2$ Simmonds PC, Primrose JN, Colquitt JL, Garden OJ, Poston GJ, Rees M: Surgical resection of hepatic metastases from colorectal cancer: a systematic review of published studies. Br J Cancer 2006;94:982-999.

>3 Rougier P, Milan C, Lazorthes F, Fourtanier G, Partensky C, Baumel H, et al: Prospective study of prognostic factors in patients with unresected hepatic metastases from colorectal cancer. Fondation Francaise de Cancerologie Digestive. Br J Surg 1995;82:13971400 .

-4 Isenberg J, Fischbach R, Kruger I, Keller HW: Treatment of liver metastases from colorectal cancer. Anticancer Res 1996;16:12911295.

5 Covey AM, Brown KT, Jarnagin WR, Brody LA, Schwartz L, Tuorto S, et al: Combined portal vein embolization and neoadjuvant chemotherapy as a treatment strategy for resectable hepatic colorectal metastases. Ann Surg 2008;247:451-455.

-6 Oldhafer KJ, Lang H, Malago M, Testa G, Broelsch CE: Ex situ resection and resection of the in situ perfused liver: are there still indications?. Chirurg 2001;72:131-137.

$\checkmark 7$ Rahbari NN, Zimmermann JB, Koch M, Bruckner T, Schmidt T, Elbers H, et al: IVC CLAMP: infrahepatic inferior vena cava clamping during hepatectomy - a randomised controlled trial in an interdisciplinary setting. Trials 2009;10:94.

$>8$ Dubay D, Gallinger S, Hawryluck L, Swallow C, McCluskey S, McGilvray I: In situ hypothermic liver preservation during radical liver resection with major vascular reconstruction. Br J Surg 2009;96:1429-1436.

$>9$ Hemming AW, Reed AI, Langham MR Jr, Fujita S, Howard RJ: Combined resection of the liver and inferior vena cava for hepatic malignancy. Ann Surg 2004;239:712-719, discussion 9-21.

$\checkmark 10$ Azoulay D, Eshkenazy R, Andreani P, Castaing $\mathrm{D}$, Adam R, Ichai $\mathrm{P}$, et al: In situ hypothermic perfusion of the liver versus standard total vascular exclusion for complex liver resection. Ann Surg 2005;241:277-285.

$>11$ Emond JC, Kelley SD, Heffron TG, Nakagawa T, Roberts JP, Lim RC Jr: Surgical and anesthetic management of patients undergoing major hepatectomy using total vascular exclusion. Liver Transpl Surg 1996;2:91-98.

$\checkmark 12$ Belghiti J, Noun R, Zante E, Ballet T, Sauvanet A: Portal triad clamping or hepatic vascular exclusion for major liver resection. A controlled study. Ann Surg 1996;224:155161.

$>13$ Vetelainen R, van Vliet A, Gouma DJ, van Gulik TM: Steatosis as a risk factor in liver surgery. Ann Surg 2007;245:20-30.
14 Belzer FO, Southard JH: Principles of solidorgan preservation by cold storage. Transplantation 1988;45:673-676.

15 Heaney JP, Stanton WK, Halbert DS, Seidel J, Vice T: An improved technic for vascular isolation of the liver: experimental study and case reports. Ann Surg 1966;163:237-241.

16 Fortner JG, Shiu MH, Kinne DW, Kim DK, Castro EB, Watson RC, et al: Major hepatic resection using vascular isolation and hypothermic perfusion. Ann Surg 1974;180:644652.

17 Pichlmayr R, Grosse H, Hauss J, Gubernatis G, Lamesch P, Bretschneider HJ: Technique and preliminary results of extracorporeal liver surgery (bench procedure) and of surgery on the in situ perfused liver. Br J Surg 1990;77:21-26.

18 Hannoun L, Delriviere L, Gibbs P, Borie D, Vaillant JC, Delva E: Major extended hepatic resections in diseased livers using hypothermic protection: preliminary results from the first 12 patients treated with this new technique. J Am Coll Surg 1996;183:597-605.

19 Fabre JM, Domergue J, Fagot H, Guillon F, Souche B, Joswik M, et al: Leiomyosarcoma of the inferior vena cava presenting as BuddChiari syndrome. Vena cava replacement under veno-venous bypass and liver hypothermic perfusion. Eur J Surg Oncol 1995;21: 86-87.

20 Raab R, Schlitt HJ, Oldhafer KJ, Bornscheuer A, Lang H, Pichlmayr R: Ex-vivo resection techniques in tissue-preserving surgery for liver malignancies. Langenbecks Arch Surg 2000;385:179-184.

21 Belghiti J, Dousset B, Sauvanet A, Lipinska E, Aschehoug J, Fekete F: Preliminary results with 'ex situ' surgery for hepatic tumors: an alternative between palliative treatment and liver transplantation? (in French). Gastroenterol Clin Biol 1991;15:449-453.

22 Schlitt HJ, Oldhafer KJ, Bornscheuer A, Pichlmayr R: In-situ, ante-situm, and ex-situ surgical approaches for otherwise irresectable hepatic tumors. Acta Chir Austriaca 1998;30:215-219.

23 Delriviere L, Hannoun L: In situ and ex situ in vivo procedures for complex major liver resections requiring prolonged hepatic vascular exclusion in normal and diseased livers. J Am Coll Surg 1995;181:272-276.

24 Kim YI, Hiratsuka K, Kitano S, Joo DH, Kamada N, Sugimachi K: Simple in situ hypothermia reduced ischaemic injury to human liver during hepatectomy. Eur J Surg 1996; 162:717-721.

25 Hannoun L, Balladur P, Delva E, Panis Y, Camus Y, Honiger J, et al: 'Ex situ-in vivo' surgery of the liver: a new technique in liver surgery. Principles and preliminary results (in French). Gastroenterol Clin Biol 1991;15: $758-761$.
26 Forni E, Meriggi F: Bench surgery and liver autotransplantation. Personal experience and technical considerations. G Chir 1995; 16:407-413.

27 Vaillant JC, Borie DC, Hannoun L: Hepatectomy with hypothermic perfusion of the liver. Hepatogastroenterology 1998;45:381388.

28 Azoulay D, Andreani P, Maggi U, Salloum C, Perdigao F, Sebagh M, et al: Combined liver resection and reconstruction of the suprarenal vena cava: the Paul Brousse experience. Ann Surg 2006;244:80-88.

29 Kim Z, Jeong GA, Chung JC, Chu CW, Shin EJ, Kim HC: Ante-situm liver resection in recurrent liver metastasis from colorectal cancer. Hepatogastroenterology 2009;56:508511.

30 Hemming AW, Reed AI, Fujita S, Zendejas I, Howard RJ, Kim RD: Role for extending hepatic resection using an aggressive approach to liver surgery. J Am Coll Surg 2008;206: 870-875, discussion 5-8.

31 Takeuchi K, Ohira M, Yamashita T, Sowa M: An experimental study of hepatic resection using an in situ hypothermic perfusion technique. Hepatogastroenterology 1997; 44: 1281-1294.

32 Stockmann M, Lock JF, Riecke B, Heyne K, Martus P, Fricke M, et al: Prediction of postoperative outcome after hepatectomy with a new bedside test for maximal liver function capacity. Ann Surg 2009;250:119-125.

-33 Stockmann M, Lock JF, Malinowski M, Niehues SM, Seehofer D, Neuhaus P: The LiMAx test: a new liver function test for predicting postoperative outcome in liver surgery. HPB (Oxford) 2010;12:139-146.

34 Malhi H, Gores GJ: Cholangiocarcinoma: modern advances in understanding a deadly old disease. J Hepatol 2006;45:856-867.

35 Adam R, Delvart V, Pascal G, Valeanu A, Castaing D, Azoulay D, et al: Rescue surgery for unresectable colorectal liver metastases downstaged by chemotherapy: a model to predict long-term survival. Ann Surg 2004; 240:644-657, discussion 57-58.

-36 Melendez J, Ferri E, Zwillman M, Fischer M, DeMatteo R, Leung D, et al: Extended hepatic resection: a 6-year retrospective study of risk factors for perioperative mortality. J Am Coll Surg 2001;192:47-53.

37 Dixon E, Bathe OF, McKay A, You I, Dowden $\mathrm{S}$, Sadler D, et al: Population-based review of the outcomes following hepatic resection in a Canadian health region. Can J Surg 2009; 52:12-17.

38 Dixon E, Schneeweiss S, Pasieka JL, Bathe OF, Sutherland F, Doig C: Mortality following liver resection in US medicare patients: does the presence of a liver transplant program affect outcome? J Surg Oncol 2007;95: 194-200. 
39 Glasgow RE, Showstack JA, Katz PP, Corvera CU, Warren RS, Mulvihill SJ: The relationship between hospital volume and outcomes of hepatic resection for hepatocellular carcinoma. Arch Surg 1999;134:30-35.

40 Hollenbeck BK, Dunn RL, Miller DC, Daignault S, Taub DA, Wei JT: Volume-based referral for cancer surgery: informing the debate. J Clin Oncol 2007;25:91-96.

41 Fong Y, Gonen M, Rubin D, Radzyner M, Brennan MF: Long-term survival is superior after resection for cancer in high-volume centers. Ann Surg 2005;242:540-544, discussion 4-7.
42 Choti MA, Bowman HM, Pitt HA, Sosa JA, Sitzmann JV, Cameron JL, et al: Should hepatic resections be performed at high-volume referral centers? J Gastrointest Surg 1998;2:11-20.

43 Miyazaki M, Ito H, Nakagawa K, Ambiru S, Shimizu H, Okuno A, et al: Aggressive surgical resection for hepatic metastases involving the inferior vena cava. Am J Surg 1999; 177:294-298.

44 Oldhafer KJ, Lang H, Schlitt HJ, Hauss J, Raab R, Klempnauer J, et al: Long-term experience after ex situ liver surgery. Surgery 2000;127:520-527.

45 Hemming AW, Reed AI, Langham MR, Fujita S, van der Werf WJ, Howard RJ: Hepatic vein reconstruction for resection of hepatic tumors. Ann Surg 2002;235:850-858.
6 Lechaux D, Megevand JM, Raoul JL, Boudjema K: Ex vivo right trisegmentectomy with reconstruction of inferior vena cava and 'flop' reimplantation. J Am Coll Surg 2002; 194:842-845.

47 Andre T, Tournigand C, Rosmorduc O, Provent S, Maindrault-Goebel F, Avenin D, et al: Gemcitabine combined with oxaliplatin (GEMOX) in advanced biliary tract adenocarcinoma: a GERCOR study. Ann Oncol 2004;15:1339-1343.

48 Tournigand C, Andre T, Achille E, Lledo G, Flesh M, Mery-Mignard D, et al: FOLFIRI followed by FOLFOX6 or the reverse sequence in advanced colorectal cancer: a randomized GERCOR study. J Clin Oncol 2004; 22:229-237. 